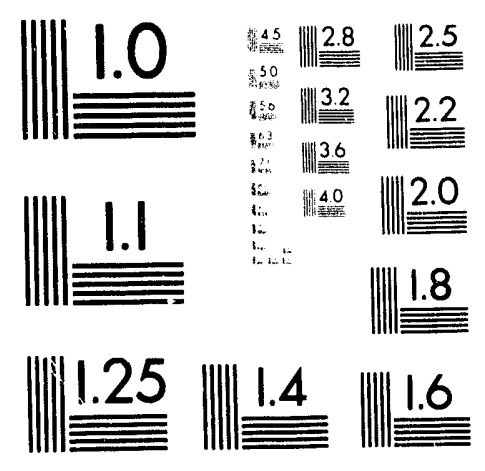



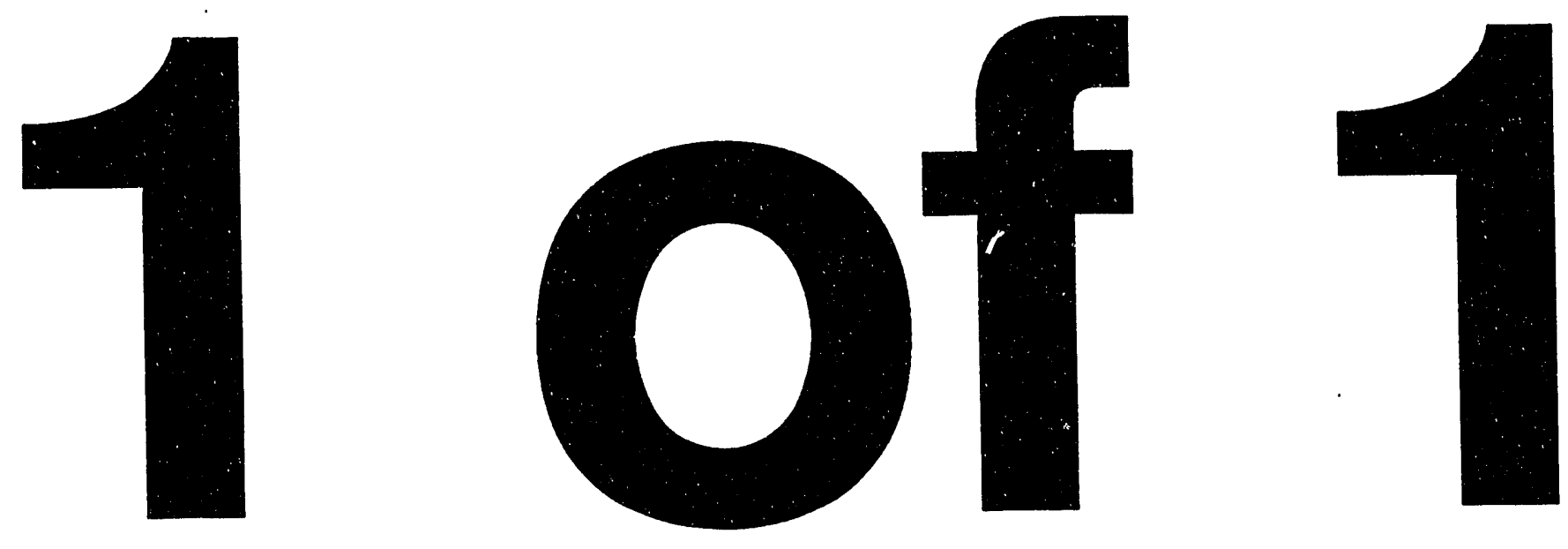


\section{Cxy $131197 \ldots 2$}

UCRL-JC-113183

PREPRINT

\section{High-Power Copper Vapor Lasers and Their Application to Precision Drilling and Cutting}

B. E. Warner

P. D. Weber

This paper was prepared for submittal to the

IEEE Lasers and Electro-Optics Society

LEOS ' 93

San Jose, California

November 15-19, 1993

July 27,1993

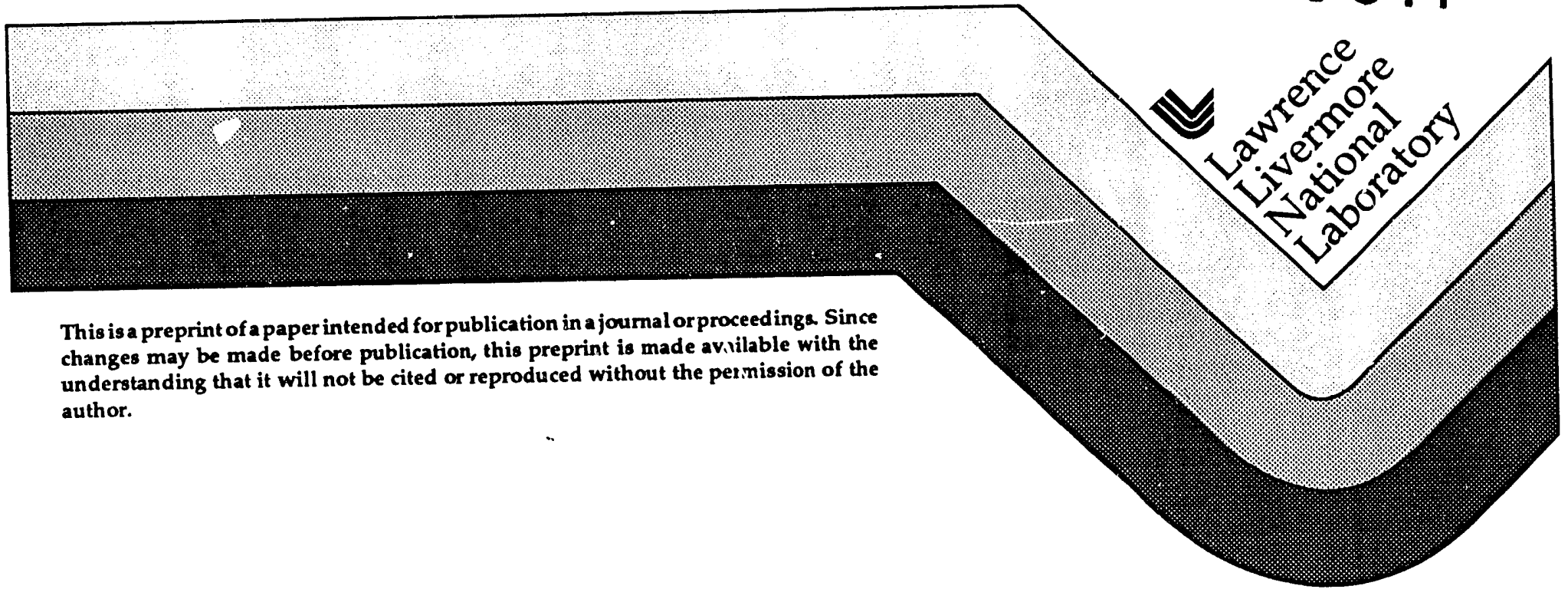
changes may be made before publication, this preprint is made avinilable with the understanding that it will not be cited or reproduced without the permission of the author. 


\section{DISCLAIMER}

This document was prepared as an account of work sponsored by an agency of the United States Government. Neither the United States Government nor the University of California nor any of their employees, makes any warranty, express or implied, or assumes any legal liability or responsibility for the accuracy, completeness, or usefulness of any information, apparat us, product, or process disclosed, or represents that its use would not infringe privately owned rights. Reference herein to any specific commercial products, process, or service by trade name, trademark, manufacturer, or otherwise, does not necessurily constitute or imply its endorsement, recommendation, or favoring by the United States Government or the University of California. The views and opinions of authors expressed herein do not necessarily state or reflect those of the United States Government or the University of California, and shall not be used for advertising or product endorsement purposes. 


\title{
High-Power Copper Vapor Lasers and Their Application to Precision Drilling and Cutting
}

\author{
Bruce E. Warner and Paul D. Weber \\ Lawrence Livermore National Laboratory
}

High-power copper vapor lasers (CVLs) have been under development at Lawrence Livermore National Laboratory (LLNL) for more than 15 years in support of the DOE's Program in Laser Isotope Separation. The technology is now quite mature, having met many of its goals in system architecture, power, reliability, and maintainability. Over the past several years we have begun an effort to utilize this technology in other industrial applications, such as metals processing, and have found a number of unique processes. In this paper we describe briefly the general characteristics of the CVL, our recent progress in developing the laser as an industrial tool, and our progress in using the laser in precision drilling and cutting.

Our CVLs are of two types; relatively low-power oscillators ( $30 \mathrm{~W}$ average), and highpower amplifiers (250 - $500 \mathrm{~W}$ average). These lasers emit $50 \mathrm{~ns}$ pulses of light at $510 \mathrm{~nm}$ and $578 \mathrm{~nm}$ in a $2: 1$ ratio at $4.5 \mathrm{kHz}$ repetition rate. A CVL system can be configured as a single oscillator or as oscillator-amplifier chains for high power. At LLNL we operate many oscillatoramplifier chains simultanec. sly to energize a tunable dye laser system.

Our program to demonstrate materials processing applications of the CVLs, as well as diode pumped solid state lasers, utilizes a 1000 sq.ft. laboratory equipped with two 3-axis processing tables. One table is capable of fractional mil tolerances and linear travel speeds up to 15 inches/sec. The other table, mounted on a vibration isolated structure, is capable of micron accuracy over its 6 inch travel. Into this facility we deliver, with a discrete optical system, CVL (and high-power dye laser) light up to $750 \mathrm{~W}$ and with reconfiguration up to $1500 \mathrm{~W}$. In addition, we have installed a fiber injection system and routinely deliver up to $100 \mathrm{~W}$ of visible light with $0.6 \mathrm{~mm}$ core diameter optical fiber.

Recent LLNL advances in CVL technology: In the last several years, LLNL has made significant progress in technology areas that are important for industrialization of the CVL; improvements in beam quality, scaling of amplifier power levels, and demonstration of high reliability. Precision materials processing requires near diffraction limited beam quality. We have developed an injection seeding technique, coupled with a self-imaging unstable resonator, to produce near diffraction limited beams at nominally $30 \mathrm{~W}$ output power. ${ }^{1}$ The use of this highbeam quality oscillator with an amplifier has resulted in better than 3 times diffraction limited CVL beams at the several hundred watt level. We are continuing to work on amplifier window improvements to minimize thermal distortion in order to routinely reach diffraction limited amplifier performance.

Scaling of CVL amplifier power levels has been very important to the economics of laser isotope separation since minimizing of the number of parallel beam lines to produce a required system power level reduces the costs associated with optical delivery, support equipment, and facility. By the mid 1980's, LLNL had demonstrated a $200-250 \mathrm{~W}$ CVL amplifier that employed an $8 \mathrm{~cm}$ diameter by 3 meter gain volume. This amplifier tended to have higher gain on the wall than in the center of the volume because of deleterious thermal effects and associated limits in electric field diffusion into the large volume. ${ }^{2}$ Scaling to higher-amplifier power levels required addressing these limitations. Based on a concept that originated in the carly 1980's, LLNL developed and engineered an alternate configuration for the CVL amplifier. This configuration, called an S-laser, employs a cylindrical plasma tube with an internal, longitudinal, segmented, cooling vane made of a refractory metal that bisects the optical aperture. This configuration allows deposited discharge heat to diffuse a shorter distance, either to the wall directly or to the internal cooling vane, where it radiates to the wall, thereby reducing internal gas temperatures significantly and reducing thermal effects. With little added cost, this modification increases optical power by $25 \%$ over cylindrical configurations at the $8 \mathrm{~cm}$ diameter size and helps to homogenize the gain profile both temporally and spatially. Based on the knowledge gained in many hundreds-of- 
thousands of unit operating hours of the S-lasers, LLNL developed and engineered a nextgeneration amplifier. Within the same enclosure dimensions, this advanced amplifier produces $500 \mathrm{~W}$ of average power. In 1992, two 3-amplifier chains of these lasers produced $2500-3000$ $\mathrm{W}$ average power continuously for greater than $1000 \mathrm{~h}$, without a failure.

As part of LLNL's effort to demonstrate CVL technology for DOE, detailed laser reliability, availability, and maintainability (RAM) data have been accumulated. The relatively mature oscillator and S-laser hardware has demonstrated mean-time-between-failure (MTBF) of 1800 and $1200 \mathrm{~h}$ respectively. This includes all random failures. With approximately one year of operating experience, the advanced amplifiers have demonstrated good initial reliability, with a MTBF of about $1 / 2$ of that of our mature CVLs.

Application to precision drilling and cutting: Initially funded internally by LLNL research funds, the Laser Materials Processing (LMP) facility has been investigating the advantages of using CVL, high-power dye, ${ }^{3}$ and advanced diode-pumped solid-state lasers ${ }^{4}$ for industrial processing problems. To date, several advantages of these high-radiance sources have become apparent. The CVL has shown good promise for precision drilling and cutting because of its highbeam quality at high-average power and pulse repetition rate. Its short pulse length gives it advantages in ablative material removal, good coupling to traditionally difficult to process materials, and efficient conversion of material to vapor.

We have begun a physics modeling effort of nanosecond-pulse-length visible-laser drilling of metals. ${ }^{5}$ Our initial focus has been to model CVL beam processing of iron, but the model is equally applicable to a Q-switched, second harmonic Nd:YAG laser, and other metals. Focusing a $30 \mathrm{~W}(4 \mathrm{kHz}) \mathrm{CVL}$ to a $50 \mathrm{~mm}$ spot produces a peak irradiance of $10^{10} \mathrm{~W} / \mathrm{cm}^{2}$. Under these conditions, the irradiated metal reaches $5000 \mathrm{C}$ temperature in roughly a nanosecond. The ablated material creates a shock wave as it expands from the surface. Directed velocities of $10^{5} \mathrm{~cm} / \mathrm{sec}$ have been calculated and observed in the laboratory. Our preliminary calculations do not show a high enough plasma density to directly absorb the visible laser light, indicating an advantage ove: infrared lasers.

We have utilized our CVLs, and high-power dye lasers, to drill and cut metal sheet. For thin material, $<1.0 \mathrm{~mm}$, we find drilled holes and kerf widths as small as 20 to $30 \mathrm{~mm}$ with depthto-width aspect ratios ranging from 5:1 to as high as 50:1. With thin metals, we have observed drilled holes and narrow cuts with virtually no heat affected zone $(<1 \mathrm{~mm})$. Examples of successfully drilled, or cut materials, are stainless steel, aluminum, copper, tungsten, and epoxy composites. Our CVL drilling rates and efficiencies compare well, and of ten exceed, those measured by Dr. R. Poprawe 6 for the $248 \mathrm{~nm} \mathrm{KrF}$ excimer laser.

The Laser Materials Processing Program at LLNL continues to utilize its laser sources to develop and transfer manufacturing and processing solutions to industry. The high-power CVL is a unique tool (that as yet, is not generally available to industry) and shows promise to fulfill specialized processing requirements, particularly in precision drilling and cutting.

Work performed under the auspices of the U.S. D.O.E. by LLNL under Contract No. W-7405-Eng-48.

\section{References}

1. J.C.Chang and M.Solarski, "A Self-Imaging Injection-locked Copper Laser Oscillator" CLEO Conference, May 1993.

2. M.J. Kushner and B.E. Warner, "Large-bore copper-vapor lasers: Kinetics and scaling issues," J. Appl. Phys. 54 (6), p. 2970, June 1983.

3. R.P. Hackel and B.E. Warner, "The copper-pumped dye laser system at Lawrence Livermore National Laboratory," SPIE Vol. 1859, p. 120, 1993.

4. B. Comanski et.al.,"1000-W diode pumped folded zig zag slab laser," CLEO Conference, May 1993.

5. C.D. Boley, R.A. London, and J.T. Early, LLNL, private communication.

6. R. Poprawe, "Disintegration of material and plasma formation in the radiation field of UVlasers," Ph.D. Thesis, Technical University of Darmstadt, 1984. 

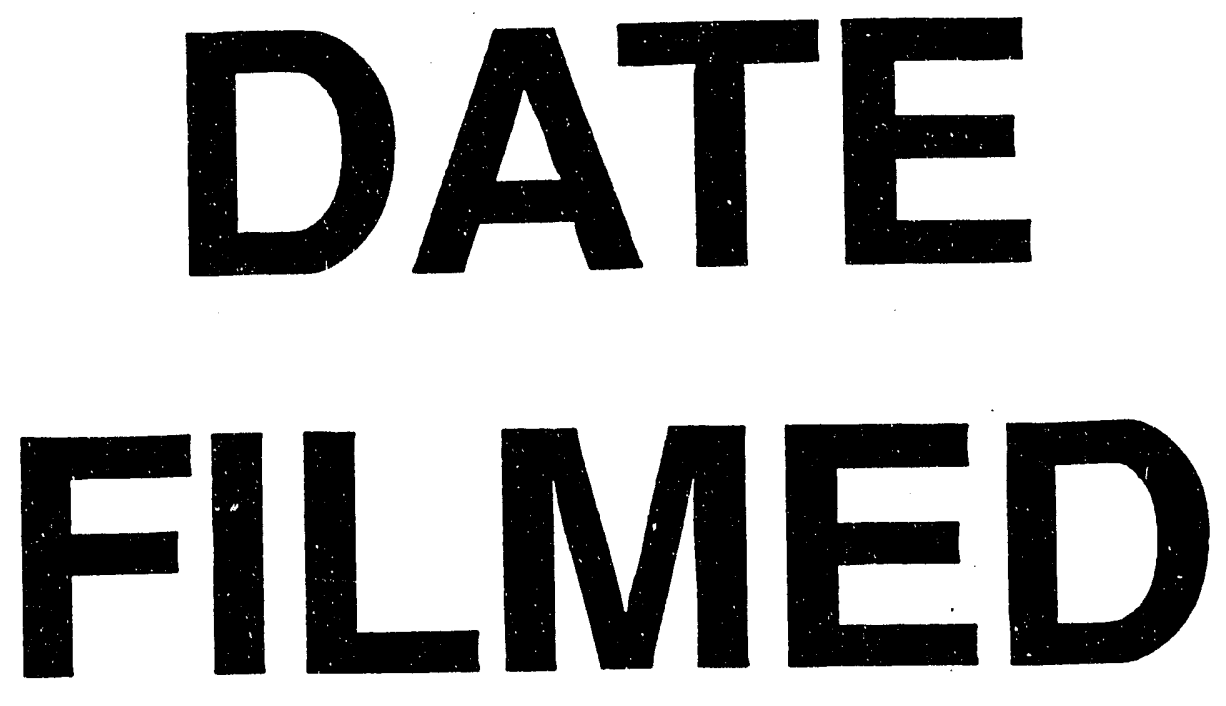

$11 / 10 / 93$
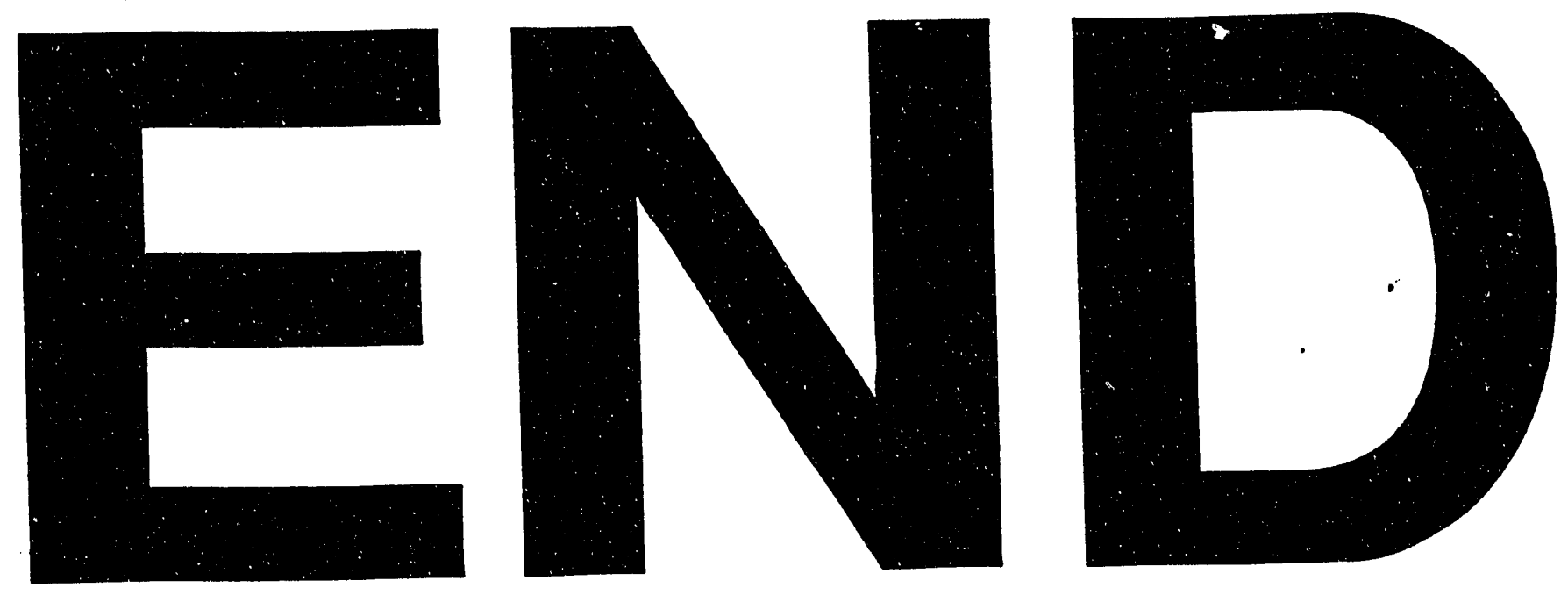
